\title{
The balance model for heat transport from hydrolytic reaction mixture
}

\author{
Dagmar Janacova ${ }^{1 *}$, Karel Kolomaznik ${ }^{1}$, Pavel Mokrejs ${ }^{2}$, Vladimir Vasek ${ }^{1}$, Jiri Krenek ${ }^{1}$ and Ondrej Liska ${ }^{3}$ \\ ${ }^{1}$ Tomas Bata Univerzity in Zlín, Faculty of Applied Informatics, nám. T.G.Masaryka 5555, 76001 Zlín, Czech Republic \\ 2 Tomas Bata Univerzity in Zlín, Faculty of Technology, nám. T.G.Masaryka 5555, 76001 Zlín, Czech Republic \\ ${ }^{3}$ Technical University of Kosice, Faculty of Mechanical Engineering, Department of Automation, Control and Human Machine \\ Interaction, Letná 9, 04200 Košice, Slovakia
}

\begin{abstract}
The content of the paper is the industrial application of enzyme hydrolysis of tanning solids waste with a view to minimizing the price of enzyme hydrolysate product, which has widely used. On the base of the energy balance of the enzymatic hydrolysis we estimated the critical minimal charge of a tanning drum. We performed of the critical minimal on the basis of a balance model for heat transport from reaction mixture into the environment through reactor wall. Employing a tanning drum for hydrolytic reaction allows to process tanning wastes in the place of their origin. It means thus considerably to enhancing economics of the whole process.
\end{abstract}

\section{Introduction}

Although the leather industry is environmentally important as a user of the byproduct of the meat industry, it is perceived as a consumer of resources and a producer of pollutants. In order to reach the status of future sustainability the industry must aim to the treatment of inorganic and organic waste. Czech Republic as potential member of $\mathrm{EU}$ is also required to operate within strict legislative boundaries [1]. A sustainable industry for the future most radically change the philosophy of the leather making process through optimal resource management within the tannery. The result of this will be closed loop, clean systems operating towards zero waste for the production of high quality niche leather and other valuable collagenic materials. The function of the beam-house is to clean, purify and retain structural integrity of the collagen protein in preparation for subsequent tanning process, which technically coverts protein to leather.

\section{Heat balance of enzymatic hydrolysis}

Enzymatic hydrolysis: At present this method offers the best prospects for the future. The main advantage of using proteolytic enzymes as the catalyst for the process of hydrolysis is that moderate reaction conditions can be employed. The reaction takes place at a temperature $70^{\circ} \mathrm{C}$, a pH value between 8 and 9 , and under atmospheric pressure. Furthermore, the molecular weight of the resulting proteineous product can be influenced by altering the composition of the reaction mixture and adjusting the addition of enzymes. This provides the flexibility to the process allowing it to produce products of different specifications in response to customer requirements.

The industrial application can came to the reality in case of connection with the preparation of regenerated tanning liqueur from chromium filtrate sludge, because the price of natrium dichromate is relative expensive. Another possibility to degrease the operating costs is in using of solar pans for the concentration or drying dilute protein hydrolyzates. A further possibility in reducing prices of protein hydrolyzates consists in reducing investment costs. The chief problem consisted in holding the temperatures of reaction mixture within such limits as to arrive at a comparable yield of soluble protein after the practically same time as when an isothermal reactor was used. A further effort of ours aimed at the tanning drum not having to be constructionally adapted. In theory, our tanning drum represents a non isothermal and non adiabatic reactor.

In order to try out various possibilities of setting up parameters, preliminary calculations were performed simulating the course of reaction mixture temperature in time dependently on its initial value, and on content of drum.

The temperature of reaction mixture in dependence on time may be calculated by resolving a mathematical model representing the hydrolytic reaction. In an effort at reaching a fast solution we set up a determinist model in accordance with simplified conditions as follow:

- the reaction mixture is intimately stirred by motion of drum

- heat transfer is perfect on both sides of drum wall

- reaction heat of hydrolysis is negligible

* Corresponding author: janacova@,fai.utb.cz 
- drum has the shape of a cylinder, its radius being at least 10 times greater than thickness of wall so that the temperature field in wall may be described by an "infinite plate" model

- dependence of all physical parameters of the model on temperature is negligible

- assuming these, we applied the following mathematical model.

$$
\begin{aligned}
\frac{\partial t(x, \tau)}{\partial \tau}=a \frac{\partial^{2} t}{\partial x^{2}}(x, \tau) ; 0<x<b ; \tau>0 \\
m_{0} c_{0} \frac{\partial t_{0}(\tau)}{\partial \tau}=S \lambda \frac{\partial t}{\partial x}(0, \tau) \\
t(x, 0)=t_{p} \\
t(b, \tau)=t_{p} \\
t(0, \tau)=t_{0} \\
t_{0}(0)=t_{o p}
\end{aligned}
$$

Equation (1) describes a non-stationary temperature field in the wall of drum. Heat balance expressing equilibrium between rate of decrease in reaction mixture temperature and transfer of heat through reactor wall is described by equation (2). Equations (3) and (4) are initial conditions, and equations (4) and (5) describe conditions of perfect heat transfer. For analytical solution of the given model, Laplace transformation was applied yielding:

$$
\frac{t_{0}-t_{p}}{t_{o p}-t_{p}}=2 \sum_{n=1}^{\infty} \frac{\cos \left(q_{n}\right) \sin \left[(1-X) q_{n}\right]}{q_{n}+\sin \left(q_{n}\right) \cos \left(q_{n}\right)} e^{-F_{0} q_{n}^{2}}
$$

where $q_{n}$ are roots of the following equation,

$$
\cot (q)=q . R a
$$

$F_{o}$ is the Fourier criterion (dimensionless time)

$$
\begin{gathered}
F_{0}=\frac{a \tau}{b^{2}} \\
X=\frac{x}{b}
\end{gathered}
$$

and $R a$ is a dimensionless number expressing the ratio of reaction mixture enthalpy and enthalpy of drum wall.

$$
R a=\frac{m_{o} c_{o} \Delta t_{o}}{m c \Delta t}
$$

Equation (7) is the calculated temperature dependence of reaction mixture on time in a dimensionless expression of both variables. The course of reaction mixture temperature in time depends on thickness of wall $b$, its coefficient of thermal conductivity $a$, mass $m$, specific heat $c$ and also on the mass of reaction mixture $m_{o}$ and on its specific heat $c_{o}$. The dimensionless value of reaction mixture $t_{0}(\tau)$ then depends on its initial temperature top and ambient temperature $t_{p}$, which is identical with the temperature of tanning drum wall. The only value among all those mentioned that we can practically change is the mass of charge into reactor (reaction mixture) $m_{o}$ by means of which the value of dimensionless parameter $R a$ can be affected. Hence, such a charge of reaction mixture $m_{o}$ and its initial temperature top have to be selected that temperature during the necessary reaction time does not drop under a limit where reaction rate would be very small. The minimal charge is given by value $R a$, i.e. point $K$, and all other charges by value of parameter $R a$ of curves to the right of point $K$. When practically performing hydrolysis in a tanning drum, its walls can be preheated with hot water or thermally insulated. The minimal drum charge can thus be reduced and even smaller plant put to use. In case the drum walls are heated, critical charge quantity may be estimated by employing a quasi-stationary model.

$$
-c_{0} m_{0} \frac{d t_{0}}{d \tau}=\frac{\lambda}{b} S\left(t_{0}-t_{p}\right)
$$

Its solution gives

$$
\ln \left(\frac{t_{o p}-t_{p}}{t_{0}-t_{s}}\right)=\frac{\lambda S \tau}{b m_{0} c_{0}}
$$

The non-stationary temperature field in drum wall is shown in Fig. 1 (for $R a=4$ ), and the time course of temperature of the reaction mixture in drum in Figure 2 (equation 7 for $\mathrm{x}=0$ ).

\section{Practical part}

\subsection{Description of test}

Plant at our disposal comprised a tanning drum of $2 \mathrm{~m}$ diameter, 1-m width, wall thickness $5 \mathrm{~cm}$. We filled the drum with hot water of known mass and starting temperature of $70^{\circ} \mathrm{C}$.

An aperture was drilled in the drum wall and an alcohol thermometer fixed/tightly inserted/therein so that its tip reached sufficiently far into hot liquid.

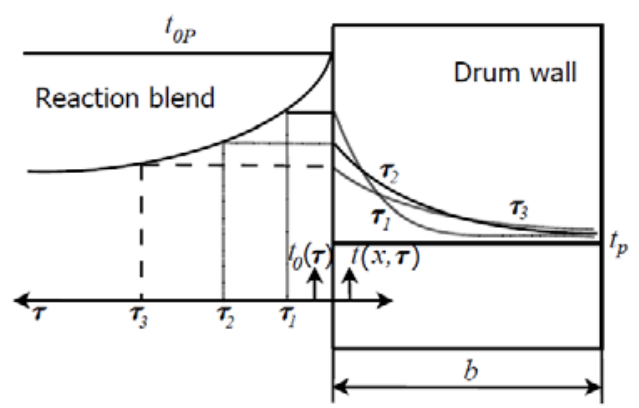

Fig. 1. The non-stationary temperature field in drum wall. 
Temperature of water inside the rotating drum was measured at regular intervals. As soon as rate of temperature decrease sank/got under $0.05{ }^{\circ} \mathrm{C} / \mathrm{min}$, cooled water was let out and drum refilled with hot water of known starting temperature and mass.

\subsection{Determining the coefficient of heat conductivity through drum wall}

When determining the coefficient of drum heat conductivity, we start from relation (7) and from experimental data of the dependency of water temperature inside the rotating drum on time. In case the time is long enough, members of the infinite series on the right side of equation (7) except for the first, may be neglected, and from the condition thus simplified the value of temperature parameter may be calculated.

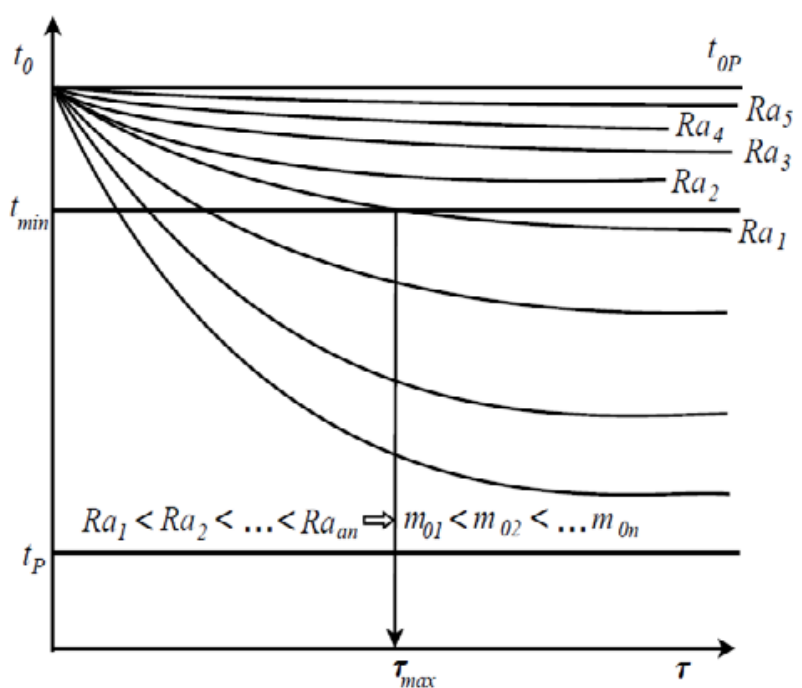

Fig. 2. The non-stationary temperature field in drum wall for variable $R a$.

Considering that the pre-exponential member is independent of time, plotting the logarithm of dimensionless temperature against time produces a straight line from which we may determine the sought-after heat conductivity of drum wall.

$$
\begin{gathered}
\frac{t_{0}-t_{p}}{t_{0}-t_{p}}=t^{*}=K e^{-\frac{a \tau}{b^{2}} q_{1}^{2}} \\
\ln t^{*}=\ln K-\frac{a q_{1}^{2}}{b^{2}} \tau
\end{gathered}
$$

Following table 1 presents experimentally measured temperatures of water in the drum dependently on time.
Table 1. Test measurements of water temperature inside drum.

\begin{tabular}{|c|c|c|c|}
\hline $\boldsymbol{\tau}$ & $\boldsymbol{t}_{\boldsymbol{0}}$ & $\boldsymbol{t}^{*}$ & $\ln t^{*}$ \\
\hline 40 & 52.8 & 0.589 & -0.530 \\
\hline 50 & 51.5 & 0.565 & -0.571 \\
\hline 60 & 50.4 & 0.544 & -0.608 \\
\hline 70 & 49.5 & 0.528 & -0.639 \\
\hline 80 & 48.7 & 0.513 & -0.668 \\
\hline 90 & 48.1 & 0.506 & -0.689 \\
\hline 100 & 47.5 & 0.491 & -0.712 \\
\hline 110 & 46.9 & 0.480 & -0.735 \\
\hline 120 & 46.5 & 0.472 & -0.750 \\
\hline 130 & 45.8 & 0.459 & -0.778 \\
\hline 140 & 45.2 & 0.448 & -0.803 \\
\hline
\end{tabular}

The same is graphically displayed in following Figure 3.

The figure 4 serves to determine gradient of linear time dependence of the natural logarithm of dimensionless water temperature in the drum.

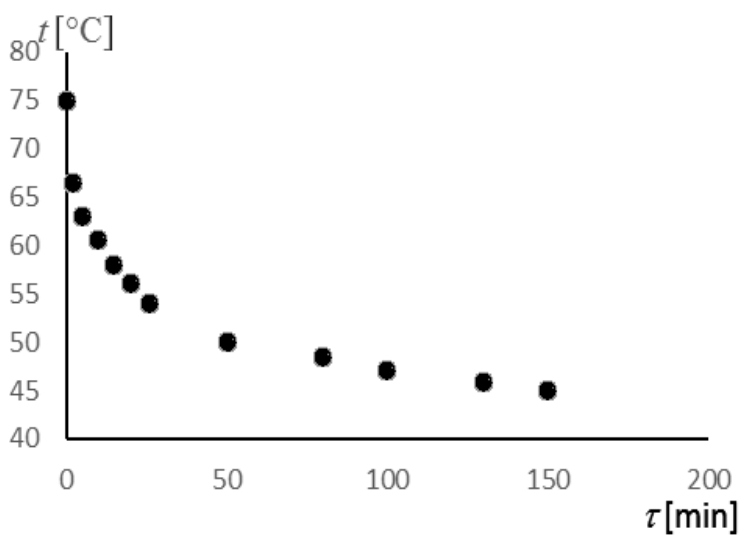

Fig. 3. Experimentally obtained data.

Applying regression analysis to experimentally obtained data presented in Fig. 3 and Table.1, we determined the line gradient $-0.0026 \mathrm{~min}^{-1}$.

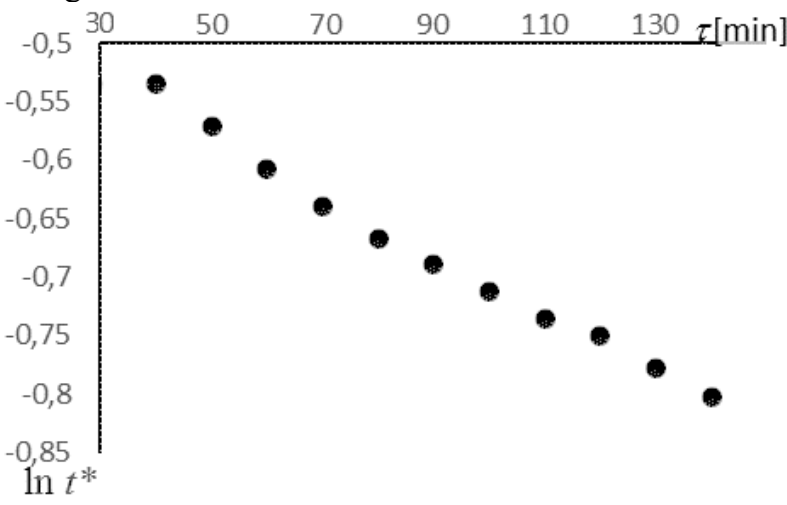

Fig. 4. The line gradient

According to (13), the mentioned value equals $-\frac{a q_{1}^{2}}{b^{2}}$. If we estimate criterion $R a$ equals 0.6 with a water content of $165 \mathrm{~kg}$ in drum and the corresponding first root of equation (8) $q_{1}$ equals 1.02 . 
We may calculate effective heat conductivity $a=9.5 \cdot 10^{-}$ ${ }^{8} \mathrm{~m}^{2} \mathrm{~s}^{-1}$. Comparing this value to that of oak wood, 1.3.10 $10^{-7} \mathrm{~m}^{2} \mathrm{~s}^{-1}$, we may claim our calculated value is realistic.

Modified enzymatic hydrolysis of chrome shavings under conditions of an isothermal stirred reactor was described in detail in the work [3]

\section{Conclusion}

Tests in a preheated drum demonstrated the process of hydrolysis could be realised on this plant, thereby making possible the direct processing of tanned wastes where these immediately originate. Investment costs will also be considerably reduced in this way and thus also the price of hydrolysis products. An approximate estimate of minimal charge for a heated drum can utilise a quasi-stationary model. The critical minimal charge of a tanning drum was estimated. An estimate was performed of the critical minimal on the basis of a balance model for heat transport from reaction mixture into the environment through reactor wall. Employing a tanning drum for hydrolytic reaction allows to process tanning wastes in the place of their origin, thus considerably enhancing economics of the whole process.

\section{List of used symbols}

$t$ - temperature of drum wall $\left[{ }^{0} \mathrm{C}\right]$,

$t^{*}$ - dimensionless temperature [ 1$]$,

$t_{0}$ - temperature of reaction mixture $\left[{ }^{0} \mathrm{C}\right]$,

$t_{p}$ - initial temperature of drum wall $\left[{ }^{0} \mathrm{C}\right]$,

$t_{o p}$ - initial temperature of drum charge $\left[{ }^{0} \mathrm{C}\right]$,

$t_{s}$ - drum ambient temperature $\left[{ }^{0} \mathrm{C}\right]$,

$\tau$ - time $[\mathrm{s}$ ],

$a$ - temperature conductivity coefficient $\left[\mathrm{m}^{2} \mathrm{~s}^{-1}\right]$,

$x$ - coordinate of drum wall [ $\mathrm{m}$ ],

$b$ - thickness of drum wall [ $\mathrm{m}]$,

$m_{o}$ - mass of reaction mixture in drum [ $\mathrm{kg}$ ],

$c_{o}$ - specific heat of reaction mixture $\left[\mathrm{J} \mathrm{kg}^{-1} \mathrm{~K}^{-1}\right]$,

$c$ - specific heat of drum walls $\left[\left[\mathrm{J} \mathrm{kg}^{-1} \mathrm{~K}^{-1}\right]\right.$.

$S$ - total area of drum inner walls (exchange area) $\left[\mathrm{m}^{2}\right]$,

$\lambda$ - heat conduct. coefficient of drum wall $\left[\mathrm{W} \mathrm{m}^{-1} \mathrm{~K}^{-1}\right]$,

$m$ - mass of drum walls [ $\mathrm{kg}$ ]

\section{Acknowledgement}

The research work is supported by the Project of the Structural Funds of the EU, Operational Programme Research and Development, Measure 2.2 Transfer of knowledge and technology from research and development into practice and by the Ministry of Education, Youth and Sports of the Czech Republic within the National Sustainability Programme project No. LO1303 (MSMT-7778/2014) and also by the European Regional Development Fund under the project CEBIA-Tech No. CZ.1.05/2.1.00/03.0089

\section{References}

1. K. Kolomazník et al., ERB 3512 PL 940974 (COP 974) Northampton, (1996)

2. L. Vasek, V. Dolinay, IFAC-PapersOnLine, 49 (27), pp. 413-418, (2016)

3. D. Janáčová, K. Kolomazník, V. Vašek, In 14th International Congress of Chemical and Process Engineer. Praha : CSChE. ISBN 80-86059-30-8, (2000)

4. L. Vasek, V. Dolinay, 27th European Conferenc, ECMS 2013, pp. 453-458. (2013)

5. W. H. Hartford Proccedings Chromium Symposium 1986: Inc. Pittsburg, Pa. p. 112, (1986)

6. O. Kirk Encyclopedia of Chemical Technology, $4^{\text {th }}$. Ed., Vol. 6, p. 269, N.Y. Willey, (1992)

7. A. J. Dean Lange's Handbook of Chemistry $14^{\text {th }}$. Ed., Mc. Graw-Hill, INC, N.Y, (1992)

8. C. S. Cantera, M. Giuste, A. Sofia CITEL, GonnetArgentina, (1997)

9. M. Maňas, D. Maňas, M. Staněk, M., Š. Šanda, V. Pata, Chemicke listy, 105 (17), p. 713-716 . (2011)

10. P. Božek, ICSS 2013; Wroclaw; Poland; p. 229-240. ISSN 2194-5357, (2013)

11. P. Božek, P. Pokorny, In Applied Mechanics and Materials. 611 p. 339-345. ISSN 1660-9336, (2014) 